Psychological Distress and Terrorist Engagement: Measuring, Correlating and Sequencing its Onset with Negative Life Events, Social Factors and Protective Factors

\title{
Emily Corner
}

Australian National University

\section{Paul Gill}

University College London

Corresponding Author:

Emily Corner

emily.corner@anu.edu.au

Centre for Social Research and Methods

Australian National University

Canberra, ACT 2600

Australia 


\begin{abstract}
This paper employs probability-based modelling to unpack the complex and multifaceted individual, social, and psychological processes that may provide psychological protection for individuals engaged with terrorist groups. We outline the predictors of the onset of psychological distress across two phases of terrorist involvement (pre-engagement and engagement). Using a dataset of 96 terrorist autobiographies, we conduct sequence analyses to pinpoint the onset of psychological problems and the experiences that preceded and followed this onset. The results demonstrate a complexity in the relationship between mental disorders and terrorist engagement, as well as the heterogeneity of the lived experience of 'being' a terrorist. The experience of psychological distress was mediated by numerous factors and the combination of these factors. The evidence suggests that, in certain cases, individual and group resilience may be a protective factor when an individual faces negative experiences. The presence of protective factors may not be sufficient to explain why group-actor terrorists present with a lower than expected prevalence of mental disorder. Future work should examine whether experiences commonly viewed as risk factors may be more useful in examining the occurrence of psychopathology in terrorists.
\end{abstract}

\title{
Keywords:
}

Terrorism; Psychopathology; Protective Factors; Terrorist Engagement; Psychological Distress 


\section{Introduction}

In terrorism studies, the examination of mental disorders largely focuses on their relationship with the movement towards terrorist involvement. The impact of terrorist involvement upon mental health has rarely been studied (Bubloz \& Simi, 2019; Gill \& Corner, 2017). Whilst some hypothesise that membership in a terrorist group, and the stressors that accompany this participation, including the high levels of exposure to violence and trauma, can lead to mental health problems (Horgan, 2003; Weatherston \& Moran, 2003), systematic research remains lacking. Fortunately, analogous fields of research provide much insight. For example, many studies have examined the high rates and predictors of trauma amongst military veterans (Hoge et al., 2004; Milliken, Auchterlonie, \& Hoge, 2007; White, Mulvey, Fox, \& Choate, 2012) and the preponderance of mental health problems within violent criminal cohorts (Burton et al., 1994; Cauffman et al., 1998; Hecker et al., 2013; Papanastassiou, Waldron, \& Chesterman, 2004). Group-based terrorists are often both witnesses to, and perpetrators of, violence. However, preliminary empirical evidence shows that the prevalence of mental disorder ${ }^{1}$ in terrorist group members may be lower than both lone-actor terrorists and the general population (Corner \& Gill, 2015; Corner et al., 2016). This paper investigates this discrepancy.

Research emphasises the importance of certain personal and environmental resources that buffer the effects of stress on health (Cohen \& Wills, 1985; Dohrenwend \& Dohrenwend, 1981; Garmezy, 1983; Wheaton, 1985). These protective resources can be internal (for example, self-esteem and resilience) or external (for example, social support). ${ }^{2}$ Research has

\footnotetext{
1 "Clinically recognisable collection of symptoms or behaviour associated in most cases with distress or interference with personal functions. A deviant pattern of behaviour, whether political, religious, or sexual, or a conflict between an individual and society, is not a mental disorder unless it is symptomatic of a dysfunction in the individual" (World Health Organisation, 2010).

${ }^{2}$ In this research, we follow the work of Swann, Jetten, Gomez, Whitehouse, and Bastian (2012) and consider the supportive effects of identity fusion. Swann and colleagues explain that identity fusion results in robust feelings of connectedness with the group and group members. These strong feelings nurture relational ties to
} 
shown that the detrimental effects of stress on mental health are less for individuals who possess such resources compared to those who do not (Dumont \& Provost, 1999; HermanStahl \& Petersen, 1996). Although some current risk assessment tools used by professionals tasked with countering terrorism do include protective factors when examining radicalisation and recidivism (Neo, Dillon, \& Khader, 2017; Pressman, Duits, Rinne, \& Flockton, 2018; Pressman \& Flockton, 2012), to date, there has been no empirically driven research which has investigated how individual resilience may protect an individual involved in a terrorist group from experiencing psychological distress, or how social structures and processes during engagement may strengthen an individual's psychological resilience.

Research suggests that those who demonstrate resilience following negative early life experiences may have a normal development pattern, even when faced with high levels of stress (Herman-Strahl \& Petersen, 1996). Low resilience scores in younger adults are associated with high hopelessness (Gooding, Hurst, Johnson, \& Tarrier, 2012), which detrimentally affect resilience in later life. Examining levels of resilience in early life allows us to control for its impact across individuals within the dataset. ${ }^{3}$ Those who do not demonstrate resilience in early life may be more at risk of psychological distress later in life.

When individuals become involved in a group, they form a shared identity around certain concepts and behaviours, consequently excluding others who do not share such qualities. Identity fusion (Swann, Jetten, Gomez, Whitehouse, \& Bastian, 2012) may occur as a consequence of the shared identity. In identity fusion, the boundaries that normally demarcate the personal and social selves become highly porous, allowing aspects of both the personal and

others within the group. With identity fusion, an individual retains a strong sense of personal self, which they channel into social behaviours that motivate and maintain the group.

${ }^{3}$ Those who are coded as resilient in early life were then marked and their data was examined further in a separate forthcoming paper (Corner, Clemmow, Taylor, Forthcoming). 
social self to cross over, without reducing the integrity of either self. This results in robust feelings of connectedness to both the group and individual group members. These strong feelings nurture relational ties to others within the group. Baumeister, Bratslavsky, Finkenauer, and Vohs (2001) provided evidence that challenging or traumatic experiences are more effective than positive experiences as facilitators for fusion. Given their greater exposure to trauma, it might then be expected that members of terrorist groups undergo identity fusion (Monahan, 2015; Swann et al. 2012).

The robust feelings of connectedness and social support that occur through identity fusion may act as a protective force against the stressors experienced by terrorists during engagement. Social support has been found to play a protective role in mental health across various domains including adolescents and young adults (Cohen \& Wills, 1985; Dumont \& Provost 1999), political prisoners (Başoğlu, et al., 1994), survivors of natural disasters (Kaniasty and Norris, 2008), and terrorist attacks (Drury, Cocking, \& Reicher, 2009; Hobfoll, Canetti-Nisim, \& Johnson, 2006). In terrorist groups, it is proposed that the sharing of beliefs and ideology enhances social connections and support. Group identification has also been positively linked to intergroup emotion theory (IET; Mackie, Silver, \& Smith, 2004; Zebel, Doosje, \& Spears, 2009). IET postulates that group-based emotions manifest within individuals, leading to greater feelings of identity with the group, therefore fortifying identity fusion.

Individual resilience and social support are not discrete, static, or homogenous. Social bonds have been shown to act as a mediating factor for individual resilience (Aldwin, Levenson, \& Spiro, 1994; Paton, et al., 2008). This research argues that it is the interaction between individual and social factors that increases the capacity to overcome challenging situations sustaining individual resilience. Their impact also differs across numerous domains, 
including, but not limited to cognition (Lakey, Tardiff, \& Drew, 1994; Waugh, Fredrickson, \& Taylor, 2008), age (Turner \& Marino, 1994), gender (Turner \& Marino, 1994), and culture (Kim, Sherman, \& Taylor, 2008; Ungar, 2013).

Inferential statistics typically focus on static relationships between immediate events, and human behaviors and experiences are often much more complex than such simple monocausal interactions imply. Often immediate behaviors or experiences within a timeframe are related, but they will occur due to one or more behaviors earlier in time. It is imperative to capture the more indirect behaviors and experiences, as these may be critical to how a process develops (Taylor \& Donald, 2007). Therefore, we require a methodology that identifies common experiences and behaviors, as well as individual processes. Proximity coefficients achieve this (Beune, Giebels, \& Taylor, 2010; Giebels \& Taylor, 2009; Taylor, 2006). This analytical method uses quantitative analysis to identify a sequence of behaviors that constitute a trajectory. Sequences of behaviors have been demonstrated across a wide range of situations, including marital interactions (Gottman, Markman, \& Notarius, 1977), traffic accidents (Clarke, Forsyth, \& Wright, 1999), alcohol-related violence (Taylor, Keatley, \& Clarke, 2017), rape (Fossi, Clarke, \& Lawrence, 2005), and terrorist mobilisation (Corner, Bouhana, \& Gill, 2018; Jacques \& Taylor, 2007; Jacques, 2010). The outputs allow for easy interpretation of the ways in which experiences come together over time (Taylor et al., 2008).

In this paper, we critically examine whether individual psychological and social processes moderate the negative psychological effects resulting from exposure to violence and trauma whilst involved in a terrorist group. Utilising a dataset of 96 terrorist autobiographies, we conducted sequence analyses to pinpoint the onset of psychological problems and the experiences that preceded and followed this onset. 


\section{Methods}

\section{Sample}

We utilised terrorist ${ }^{4}$ autobiographies to solicit relevant information regarding the terrorist life course. Autobiographical information is heavily reliant on autobiographical memory. Autobiographical memory plays a critical role in the construction of individual identity, accounting for what occurs, and when in a lifespan. Given this, systematic analysis of terrorist autobiographies has the potential to offer understanding of psychogenesis, thought processes, reasoning, and social construction within a terrorist life-span, previously unaccounted for in open source data. Critical analysis of autobiographical information allows for examination of underlying behavioral processes over a life course, an advantage not afforded in prevalence studies (Altier, Horgan, \& Thoroughgood, 2012; Altier, Leonard, Shortland, \& Horgan, 2017). Analysis of autobiographical data also limits participant reactivity, by facilitating the removal of contamination effects found in observation studies, the elimination of researcher-participant interactions, the removal of expectancy bias from participants, and the reduction of artificiality found in interview designs (Altier et al., 2017; Krippendorff, 2004).

We used Shapiro's bibliography as an initial source for identifying potential autobiographies (Shapiro, 2013). This yielded 108 autobiographical texts. Within this dataset, autobiographies were chosen for inclusion based on language (English and translated

\footnotetext{
${ }^{4}$ In this research, terrorism is defined as "The use or threat of action where the use or threat is designed to influence the government or to intimidate the public or a section of the public and/or the use or threat is made for the purpose of advancing a political, religious or ideological cause. Terrorism can involve violence against a person, damage to property, endangering a person's life other than that of the person committing the action, creating a serious risk to the health or safety of the public or a section of the public, or facilitating any of the above actions." (Gill, Horgan, \& Deckert, 2014, p. 425-426).
} 
documents), timeframe (due to text availability, individuals active prior to 1900 were removed), admission of action, and availability. Due to time and resource constraints, only documents that were in print or available through libraries were considered. Accounts only providing brief timeframes were excluded (e.g. Donal Donnelly, Prisoner 1082: Escape from Crumlin Road, Europe's Alcatraz; Bobby Sands, A Day in my Life $),{ }^{5}$ as were texts that portrayed an overview of the organization rather than an account of their personal journey (e.g. Naim Qassem, Hezbollah: The story from within). These criteria yielded 80 texts. Following this, further texts were sought using online repositories, bookshops, and libraries. This left 96 autobiographical accounts from 91 individuals for analysis.

The 96 autobiographies covered a range of group ideologies including ethnonationalism ( $\mathrm{n}=59)$, left-wing (21), right-wing (6), religious (4) and single-issue (1). Appendix 1 also lists the diverse militant organisations that the actors in this dataset stated that they joined during their involvement.

\section{Procedure}

To extract data from the autobiographies, we devised a codebook which contained 197 questions, covering demographics, culture, upbringing and early life experiences, mental health problems, recruitment, roles and experiences whilst engaged, social connections during engagement, ${ }^{6}$ disengagement, post-disengagement experiences, and stressors. The questions

\footnotetext{
${ }^{5}$ As the analyses conducted were examining distinct phases in a life course, autobiographies chosen for analysis gave insight into early life experiences, periods prior to engagement, during engagement, and post disengagement. Autobiographies that did not include writings on these periods were not taken forward for examination. ${ }^{6}$ Questions measured the degree of social connection with family members, peers, group members, group leaders, and security services. These questions examined the depth of association, whether the relationships were positive or negative, how connected the individual felt with others, and the level of support they gained from the relationship.
} 
were derived from previous codebooks used for open source data collection (Gill, Horgan, \& Deckert, 2014), autobiographical data collection (Altier et al., 2017), and literature on mental health (Corner \& Gill, 2015; Horgan, 2003), trauma (Agnew, 2010; Herman-Stahl \& Petersen, 1996) and terrorist engagement and disengagement (Altier et al., 2017; Horgan, Altier, Shortland, Taylor, 2017). For this investigation, data concerning psychological wellbeing, early life experiences, experiences during engagement, and social connections during engagement were of interest.

Coding included the reading of each text in its entirety, and the manual recording of a categorical answer for type of indicator, presence of indicator (yes, no, unknown, not applicable), frequency of indicator, and direct transcription from the source matched to the relevant question, with the date of the occurrence included, and a page number. Only information directly presented in the source was used. If an extract was appropriate for multiple questions, it was transcribed for each. To ensure reliability, coding of all 197 questions was assessed by an independent coder, who had in-depth knowledge of the coding procedure, but was blind to the research questions. The coder independently coded 7 (7.2\%) autobiographies. The reliability of coding achieved $82.1 \%$ agreement, and a corresponding Cohen's kappa of 0.73 , suggesting substantial coding reliability.

\section{Measures}

Due to the sensitive nature of specific subjects, such as abuse and mental disorder, there was an inherent lack of disclosure. ${ }^{7}$ Some authors may have been unwilling to disclose their

\footnotetext{
${ }^{7}$ Thirteen (11.9\%) individuals disclosed that they suffered from a mental disorder during their life. This figure is well below the general population average of $25 \%$, supporting the findings of Corner et al. (2016), who highlighted the lower than average prevalence of diagnosed mental disorder in group actor terrorists.
} 
sensitive medical histories. The autobiographies are drawn from a range of countries and cultures and research has consistently demonstrated that diagnosed mental disorder prevalence differs across the world (Kessler \& Üstün, 2008). In some cases, official diagnoses may be lacking because the individual never received professional assessment of their distress.

Considering these shortcomings, inferential analyses focused on psychological distress. ${ }^{8}$ An individual was coded as suffering from psychological distress if they gave indications of having a poor mental state. Items within the symptom scales of the Brief Symptom Inventory 18 (BSI 18, Derogatis \& Fitzpatrick, 2004) were used as a framework for identifying reported experiences of psychological distress. The BSI-18 includes items related to somatization, depression, and anxiety, and has high reliability and validity (Franke, et al., 2017). Examples of coded psychological distress include Ingo Hasselbach's suicidal ideation during terrorist engagement "I started to think of hanging myself that night. I looked around for places to do it, thinking that, just as it was a disadvantage to be as tall as I was in a firefight, it was equally a disadvantage when you wanted to hang yourself' (Hasselbach \& Reiss, 1996, p. 330), and Susan Stern's continuing mental health problems throughout her engagement: "I flopped around doing nothing for two weeks, sunk in melancholy. I continued taking downers. I drank anything to relieve my misery, to allow me to sleep" (Stern, 1975, p. 241). Psychological distress was measured at three times: pre-engagement, during engagement, and post-disengagement.

\footnotetext{
${ }^{8}$ Psychological distress was defined as the range of symptoms that may concern, confuse, or trouble an individual. Psychological distress has a wider remit than mental disorder, as it does not require a specific set of medically defined attributes. An individual suffering from psychological distress may exhibit some symptoms commonly identified across mental disorders. These symptoms may resolve without medical intervention; however, the longterm experience of such symptoms may lead to the diagnosis of a specific mental disorder. Life events influence the onset of psychological distress.
} 


\section{Data Analysis}

Initial analyses included bivariate correlations and chi-square analyses, comparing groups defined by engagement type and reporting of mental state. These techniques allow for inferences to be made concerning static associations across groups. The resulting statistics provided an overview of presence of mental health problems across periods of terrorist activity. The variables which demonstrated significant bivariate associations in the initial inferential analyses were then taken forward for sequence analyses using proximity coefficients. The proximity coefficient helps to identify how nodes within the same region of a sequence have more in common when they are temporally closer than when they occur further apart. The coefficient is 0 if the nodes under scrutiny occur at opposite ends of the sequence. However, if one node immediately precedes another, the coefficient is 1 at any point in the sequence. Values between 0 and 1 reflect the different levels of proximity between two nodes being examined, and are independent of length of sequence and frequency of node occurrence.

To generate the coefficients, experiences within each case were assigned a code (e.g., if an individual described an incidence of physical abuse, it was coded as PhysAbuse). These codes were then arranged in chronological order, starting with the earliest reported experience. Each case was then analyzed and a matrix was computed. An example of a proximity coefficient matrix is presented in Table 1 . The 10 experiences within the sequence are denoted by letters, and the matrix shows the coefficients. For example, within the sequence, $\mathrm{C}$ only occurs once, and is directly preceded by A, therefore within the matrix the proximity coefficient for $\mathrm{C}$, when preceded by $\mathrm{A}$ is 1 . $\mathrm{C}$ is not preceded by any other letter, so the rest of the column for $\mathrm{C}$ is empty, but because $\mathrm{C}$ precedes 8 other letters, the row for $\mathrm{C}$ displays numerous coefficients, which decrease in value as the sequence develops. 


\section{[Insert Table 1 here]}

To evaluate whether the observed proximities are unlikely to have occurred by chance (e.g., whether the probability of imprisonment following arrest and criminal behavior is higher than that expected under the null hypothesis), the sequence was statistically compared across the dependent variable on two or more conditions (in this case, reporting of psychological distress and non-reporting of psychological distress). The resulting test statistics were then compared to a set of statistics computed following randomisation. A randomisation test (Giebels \& Taylor, 2009; Taylor, 2006) shuffled the derived coefficients between the two groups (reporting of psychological distress and non-reporting of psychological distress) and calculated a test statistic. This calculation was permuted many times (e.g., 10,000 times), with test statistics calculated for each randomisation. This produced a range of test statistics that would be expected if the sequence were random. This range was then assessed to determine the probability of obtaining the original sequence and test statistic. The fewer times the observed test statistic appeared in the randomised series of statistics, the lower the resulting probability $(p)$ value.

\section{Results}

\section{Demographics}

Within the sample, $70.6 \%$ of individuals were male. Actors grew up across 36 countries. Most individuals grew up in working class homes (50.5\%). The majority (57.8\%) of individuals were raised in two-parent homes, with $11 \%$ of individuals being raised by at least one parent with a diagnosed mental disorder. $11.9 \%$ of the sample experienced terrorism from a young age due to the involvement of a family member. The mean age of contact with an individual involved in terrorism was 16.8 . However, the mean age of initial engagement was 22.2 , and mean age 
of disengagement was 32.7. Actors entered terrorist organisations across 75 cities in 29 countries. Thirteen $(11.8 \%)$ actors within the dataset disclosed that they suffered from a mental disorder at some point during their life span. There was a noticeable increase in psychological distress across time; $23.1 \%$ of actors reported psychological distress prior to engagement in terrorism, $45.9 \%$ reported psychological distress during engagement, and $41.9 \%$ reported psychological distress following disengagement.

To examine whether psychological distress during one period was correlated with distress in a later period, we computed Spearman's rho coefficients. Of those who suffered psychological distress prior to terrorist engagement, $71.4 \%$ also experienced psychological distress during their involvement in terrorism engagement $(\mathrm{r}(91)=.265, \mathrm{p}=.011)$, and $66.7 \%$ continued suffering distress following disengagement $(\mathrm{r}(68)=.331, \mathrm{p}=.006)$. Of those who suffered psychological distress during their terrorist involvement, $70 \%$ continued suffering distress following disengagement $(\mathrm{r}(86)=.532, \mathrm{p}<.001)$. Spearman's rho coefficients demonstrate significant positive effects. However, these effects are low, suggesting that the relationship between psychological wellbeing and time is affected by other factors.

\section{Early Life Resilience}

Chi square and associated Fisher's exact tests tested the relationship between psychological distress and early life experiences. Table 2 presents those experiences significantly associated with the self-reporting of psychological distress, with a Bonferonni correction for multiple comparisons setting the p-value at .005 .

[Insert Table 2 here] 
Those who self-reported experiencing psychological distress prior to terrorist involvement were significantly more likely to experience a range of negative early life experiences consistently identified as risk factors for psychopathology, such as suffering from physical $\left(\chi^{2}(1)=12.42, p<.001, O R=5.96\right)$ and verbal $\left(\chi^{2}(1)=5.94, p=.015, O R=5.16\right)$ abuse, a familial history of mental disorder $\left(\chi^{2}(1)=9.68, p=.002, O R=6.5\right)$, and alcohol (Fisher's exact test $=.005, O R=5.54)$ and drug abuse (Fisher's exact test $<.001, O R=9.90$ ). They were also significantly more likely to express feelings of loneliness (Fisher's exact test < $.001, O R=45.33$ ), and conduct criminal (non-terrorist related) behaviors $\left(\chi^{2}(1)=4.56\right.$, $p=.033, O R=2.93)$. Individuals who did not report experiencing psychological distress were significantly more likely to classify their familial relationships as 'good' (Fisher's exact test $=.017)$ and have children prior to involvement $($ Fisher's exact test $=.018)$.

A crude interpretation of these initial results might suggest two types of individuals prior to terrorist engagement: one type experiences a high level of psychological distress, a high number of life stressors, and engagement in other risky, criminal, or self-harming behaviors; while the other type does not report psychological distress and also has positive prosocial family relationships and responsibilities.

However, the results also highlight a group of individuals who experienced early life stressors but did not report psychological distress. These individuals might be viewed as a resilient cohort. $21.1 \%$ and $5.6 \%$ reported physical and verbal abuse respectively, yet reported no psychological distress. $7.0 \%$ had a familial history of mental disorder and reported no psychological distress. This discrepancy might also be due to a number of temporal factors, thus further emphasising the importance of moving from cross-sectional data to detailed inquiries into how psychological wellbeing is affected by multiple experiences across time 
Table 3 shows the proximity coefficient matrix for individuals who did not report suffering psychological distress for the above significant behaviors. Table 4 shows the proximity coefficient matrix for individuals who did report suffering from psychological distress. These tables illustrate how behaviors that occur closer in sequence (closer to 1) may have more of an impact on the outcome (psychological distress) than those that occur farther away (closer to 0$){ }^{9}$

The association between physical abuse preceding drug abuse was closer for individuals who did not report psychological distress $(F=3.33, p=.08)$. Due to the low frequency of reported experiences, no further differences were significant. However, it is possible to discern patterns from the data. Within the samples, individuals who did not report psychological distress reported better familial relationships prior to abuse, which were maintained after both physical and verbal abuse; whereas those who reported psychological distress did report good relationships prior to physical abuse, and did not maintain good relationships following verbal abuse. Those who reported psychological distress also showed a pattern of more self-destructive behaviors following verbal abuse. Individuals who did not report distress had a pattern of drug and alcohol abuse which started sooner after physical abuse than those who reported distress. These individuals were more likely to become socially isolated and turn to crime before substance abuse, whereas in those who did not report distress substance abuse was more likely to precede criminal behavior.

In individuals who did not report psychological distress, the birth of a child appears to halt drug abuse and criminal behaviors. In those who reported distress, alcohol abuse always preceded substance abuse, but this was more nuanced in those who did not report distress.

\footnotetext{
${ }^{9}$ Matrices are offset, as experiences can occur at multiple times during a sequence. Horizontal values show coefficients for experience prior to others listed. Vertical values show coefficients for experience following others listed.
} 
Among individuals who did report psychological distress, this reporting never preceded a family member being diagnosed with a mental disorder, physical or verbal abuse, or good familial relationships. Psychological distress was more immediate following verbal abuse, as compared to physical abuse, and was more likely to occur quickly after a family member was diagnosed with a mental disorder and social withdrawal. However, across individuals, psychological distress was more likely to precede criminal behaviors, alcohol and drug abuse.

[Insert table 3 here]

[Insert Table 4 here]

\section{Group-Level Protection}

To identify social connectedness and identity fusion, a series of variables concerning relationship ties were examined. $69.7 \%$ of actors had personal contact with members of the group's executive leadership. Within these individuals, $38.5 \%$ rated their relationship with group leaders as positive, and 50\% expressed a favorable attitude towards the leadership. Social ties between group members were also examined, with results indicating that $50.5 \%$ of actors rated their relationships with fellow group members as positive, and $52.3 \%$ described their attitude towards fellow group members as favorable. Results also indicate that $65.1 \%$ of individuals maintained external ties with family and friends outside the terrorist group. These descriptive results, alongside the earlier prevalence of $45.9 \%$ of individuals expressing psychological distress whilst engaged, initially appear to suggest a role for social connectedness helping to buffer members from psychological distress. 


\section{[Insert Table 5 here]}

Chi-square and associated Fisher's exact tests were computed to discern if the above frequencies reflected an association between enhanced social identity and connectedness within a group and psychological protection. Of the 30 variables tested, ${ }^{10}$ only five variables showed differences between individuals that approached significance. ${ }^{11}$ Individuals who reported experiencing psychological distress were more likely to act as a spy during their terrorist activities $\left(\chi^{2}(1)=7.62, p=.006, O R=7.13\right)$, and they were more likely to report having a poor relationship with leaders of the group (Fisher's exact test $=.008$ ). They were also more likely to retain friendships external to the immediate terrorist group $\left(\chi^{2}(1)=8.55\right.$, $p=.003, O R=3.25)$. Those who reported psychological distress were more likely to report problems balancing their marriage with their activities $\left(\chi^{2}(1)=4.89, p=.027, O R=4.33\right)$. They were also more likely to have trouble balancing being a parent with their activities $\left(\chi^{2}(1)=4.88, p=.027, O R=4.13\right)$. Given the lack of significant differences in protective factors between individuals who experienced psychological distress when engaged, and those who did not, no further inferential analyses were run.

Within the cohort, $65 \%$ of individuals who did not report psychological distress prior to engagement, did report psychological distress during their engagement. This, along with the evidence from the literature review, suggests that while social connectedness provides a

\footnotetext{
${ }^{10}$ These variables included commitment to the ideology of the group, opinion of the actions of the group, role within the group, being a spy, contact with group leadership, relationships with leadership, attitude toward leadership, relationships with group members, attitude towards group members, employment outside of the group, educational outside of the group, living a clandestine (underground) lifestyle, exile, training during exile, socialisation with peers outside of the group (radical and non-radical), retaining external familial ties, death of a non-radicalised family member, death of a radicalised family member, marriage, spousal involvement with group, balancing external and internal lifestyle, becoming a parent, disrespect from others, harmed due to group negligence, imprisonment, fear of harm from group, balancing lifestyle with group membership, religious conversion, disillusionment with group.

${ }^{11}$ Bonferroni correction for chi square analyses; $\mathrm{p} \leq .003$.
} 
psychological buffer which helps protects from distress, it is not sufficient to explain the low prevalence of mental health problems in group-actor terrorists.

\section{Discussion}

In this paper, we used autobiographical data to critically examine theories which propose that the low prevalence of mental disorder within group-terrorist samples may be due to individual and social protective factors which buffer members from psychological distress. This literature has tended to focus on static or cross-sectional data, and has not considered how psychological problems may manifest over time. To counter this, we used novel inferential statistics to illustrate why viewing terrorism as a state, rather than a process, is not sufficient to explain the effects of complex psychological and social processes. The analysis of proximity coefficients shows that the experience of psychological distress is determined by numerous factors individually and in combination. The results demonstrate the complexity of the relationship between mental health problems and terrorist engagement and the heterogeneity of the lived experience of 'being' a terrorist. Numerous factors mediate the experience of psychological distress within the sample. The evidence suggests that, in certain cases, individual and group resilience may be protective when individuals face negative experiences. However, the presence of protective factors alone may not be sufficient to explain why group-actor terrorists present with a lower than expected prevalence of mental disorder.

The initial quantitative prevalence data points to the need to review the way mental disorder is interpreted. The prevalence of mental disorder within group-based terrorists initially suggests that current presumptions surrounding mental disorder and terrorism may be correct (McCauley, 2004; Post, Sprinzak, \& Denny, 2003; Sageman, cited by Rotella, 2004; Sprinzak, 1990). An inherent issue with the autobiographical data was individuals' reluctance to disclose 
psychological problems. Accepted prevalence data for the general population is based on surveys, whereas self-disclosure rates from autobiographical texts are expected be far lower. Therefore, it is not surprising that many actors did not disclose such personal information. The issues surrounding lack of disclosure are illustrated in this quote from a former Irish Republican group member:

"these things are bound to have huge effects, perhaps not spoken about, because that would be... they don't want to talk about it, particularly at the political spectrum of it because it's to... bring it to the level of the ordinary... you did this for a cause, now you're beginning to descend it down into... they did it for a long time, about not cooperating with parole boards... cooperating with their psychological reviews and all that, and they knew that was really dangerous, dangerous for all of their members' selfesteem, and they had a very firm line on that, because it meant that you were ordinary... so talking about that is kinda a sort of betrayal... I am absolutely convinced is very difficult... cos you had to be special, had to be political, with nothing else involved... you were different, and your cause was political" (Interview 3, 2016).

The lack of disclosure may also be due to the diversity of cultures within the sample. Kessler and Üstün (2008) note that the overall prevalence of mental disorders differs greatly across countries, with Nigeria reporting the lowest prevalence (12\%) and the United States the highest $(47.4 \%)$. Differences in reported mental disorder prevalence can be attributed to acceptability of behaviours and awareness of symptoms (DuPaul, Schaughency, Weyandt, Kiesner, Ota, \& Stanish, 2001). Therefore, it is likely that cultural differences between actors affected the reporting of both mental disorders and psychological distress. 
Despite the low frequency of disclosure, many actors did describe suicidal ideation, chronic substance abuse, and depressive symptoms, but unless they mentioned an official psychiatric consultation or diagnosis, these symptoms were coded as psychological distress. However, despite the lack of disclosure surrounding diagnosed mental disorder, the prevalence of psychological distress within the dataset was far higher than current literature suggests, pointing to the need for valid empirical data to examine current theoretical and opinion-based hypotheses.

The initial bivariate analyses found that individuals who reported early life psychological distress were significantly more likely to experience a range of negative stressors, and are significantly less likely to report more positive, protective experiences. However, the results also suggested that there are multiple individual factors, which may suggest there is a cohort of individuals who are more psychologically resilient than others (Ong, Bergeman, Bisconti, \& Wallace, 2006; Bonnano, 2004; Born, Chevalier, \& Humblet, 1997; Dumont \& Provost, 1999; Fletcher \& Sakar, 2013; Gooding et al., 2012; Herman-Strahl \& Peterson, 1996). This small subset of terrorist actors within the dataset underwent negative life experiences but did not report psychological distress prior to their engagement in terrorism. The results indicate, however, that this cohort did go on to experience distress during engagement (65\%), and further research needs to scrutinise these individuals more closely.

Different combinations of experiences can impact on an individual's psychological wellbeing. Therefore, further quantitative analyses focused on the interaction of negative and positive experiences over time. Familial relationships appear to be an important mediating factor in the experience of psychological distress, as those who did not report distress consistently identified strong familial relationships despite abuse. The type of abuse also aids in explaining subsequent destructive behaviors. The proximity coefficients demonstrated how 
across groups, substance misuse and criminal behavior were more likely to be an outcome of early life negative experiences, and within those who reported psychological distress, there was a cycle of distress and destructive behaviors. The birth of a child appeared to be an important mediating factor in the reduction of destructive behaviors for more resilient individuals.

The results of this paper also imply that group protective factors and social identity may not be sufficient to explain why individuals do not suffer from mental disorder when involved in terrorism. Overall, $46.4 \%$ of actors reported psychological distress when engaged. However, there were no significant differences across the experiences of connected social identity and buffering from stress. Also, over half of all individuals expressed high social connections across both leaders and group members, but these distinctions did not differ across those who reported psychological distress and those who did not. Further, qualitative evidence from the autobiographical texts suggests that intense social relationships and identity fusion (Swann et al., 2012) may in some cases not be sufficient to protect an individual from the risks of engagement. This is evident in the case of Juozas Daumantas (1975), who despite consistently reporting excellent, highly cohesive relationships based on ideology, reported suffering distress due to the lifestyle of being involved in a terrorist group:

"I reviewed in my mine the hundreds of comrades-in-arms no longer in the living, the journey of all had been the same- from the battlefield to the graveyard or dunghill... When one thought about this, one wondered: Are we not made to fight under such dreadful conditions? The free, who enjoy human rights, are very likely to consider us mad because they do not know what it is to lose one's freedom. Nor do they know the sacrifices that must be made, by men and women alike." (Daumantas, 1975, p. 202). 
Other sources suggest that intense social bonds may actually play a role in psychological distress. One highly fused actor, Ann Hansen (2002), described the social connectedness she experienced during engagement:

“In early February 1981 I flew back to Ontario. I had only lived in Vancouver a few months, but so much had happened it felt like years. I liked my new friends so much that I wouldn't have left if it hadn't been a practical necessity" (Hansen, 2002. p. 53).

Hansen described a removal of previous social ties with individuals who did not share her ideology. The cell she engaged with also 'went underground' to enhance their cohesion, to help plan activities, and to avoid detection. Hansen described how the intense connectedness within the cell was detrimental to her psychological wellbeing:

"I felt truly alienated from the image I presented to the world, and from now on each of the superficial aspects of my life would be in keeping with this image. I hoped I could come to terms with it but not lose my old self... The only bond I would have with the old me would be Brent and Doug... With no friends to visit, no family to share the past with, cut off from all the cultural events we used to attend, the pressure on our mutual relationships would be immense. There would be no one else with whom we could vent our frustrations, share our fears, joys, and love. The enormity of our isolation dawned on me, and I felt so alone.” (Hansen, 2002. p. 168).

A further explanation for the inconsistency may be drawn from the evidence that the majority of individuals also maintained external relationships, a factor which may inhibit effective identity fusion (Hugenberg \& Bodenhausen, 2004; Li et al, 2002). Overall, the results point out the need for more dynamic analytical approaches to expand the current understanding beyond a static protective factor approach. 


\section{Limitations}

One issue with using autobiographical data to determine the mental state of individuals who have been involved in terrorism is the reliability of sources. Longevity of autobiographical memory is fragile, and fades over time (Berney \& Blane, 1997; Rubin Wetzler, \& Nebes, 1986; Walker, Vogl, \& Thompson, 1997). A memory is more effectively recalled if the mood at recall matches the mood at learning. Recall is also more effective when individuals are in a positive rather than negative mood (Ucros, 1989). As many of the autobiographies used in this paper were written post-engagement, and recalled unpleasant, sometimes horrific events, where possible, major incidents recalled in the autobiographies were cross-checked with historical records to identify potential inaccuracies. A larger concern within the field of terrorism is the potential for bias in autobiographical accounts. Wilson and Ross $(2001 ; 2003)$ point out that autobiographical memory recall is skewed by the need for self-enhancement, which permits individuals to maintain favorable views of themselves and their actions. Scholars note that those involved in terrorism often attempt to re-characterise their actions as legitimate, and can use their writings to put forth their ideology and tactical suggestions (Cordes, 1987; Ross, 2004).

Despite these concerns, autobiographical accounts have the potential to offer significant insight into the behavioral processes at any point in time during their life span, and can offer more revealing information than initially intended (Altier et al., 2017). Also, reminiscence bumps (Rubin, Rahhal, \& Poon, 1998) occur in autobiographical memory recall due to the novelty and stability of event onset occurring in early adulthood. Events occurring in early adulthood have a higher chance of autobiographical recall in later life (Conway \& PledellPearce, 2000; Pillemer, Goldsmith, Panter, \& White, 1988; Rubin, et al., 1998). 
These analyses were limited by the inherent complexity of examining both internal and external factors and how their presence and combination influence the onset of psychological distress. Almost 200 experiences were coded during the data collection, and every individual studied described a different trajectory and combination of experiences through both their early life and terrorist involvement, leading to highly convoluted pathways, with very little overlap. This meant that when faced with every possible combination of experiences, identifying all important mediating factors was not possible. The results regarding the impact of internal resilience are significant and complex. Internal resilience is recognised as a critical protective factor in mental health. Therefore, future research should endeavour to examine resilience in these actors.

Given that it was exceptionally difficult to discern meaningful patterns from the initial data, bivariate statistical testing was employed to reduce the amount of experiences examined with the proximity coefficients. This 'cleaning' may have impacted on the validity of the results, as proximity coefficients examine how all experiences impact upon each other within a sequence. Removal of behaviors that were not statistically different between groups may have impacted the final statistical outcomes. For example, imprisonment may be closely associated with psychological distress, but as the frequency of imprisonment was not significantly different between groups, it was not afforded further statistical examination. However, as this paper examined differences between those who reported psychological distress, and those who did not, it is also possible that the use of initial bivariate statistics may have actually removed all outliers that would have previously been assumed to be important, enhancing the validity of outcomes.

The evidence implies that for some, social support may potentially play act as a protective buffer for mental health whilst engaging in terrorist groups. However, the results 
also suggest that there are also a significant proportion of individuals within terrorist groups who do suffer from psychological distress (some of whom demonstrated resilience during negative early life experiences). Given this, it would be prudent to expect that experiencing psychological distress may be a result of experiences during engagement. To expand this investigation, further work should examine risk factors within a terrorist group, why these factors may lead to disengagement, and the challenges and risks individuals face following disengagement.

\section{Conclusion}

The results from this study suggest that the apparent low prevalence of diagnosed mental disorder among members of terrorist groups may in fact be due to a lack of disclosure. The prevalence of reported symptoms of psychological distress was much higher than both levels of diagnosed mental disorder, and those found in studies examining protective group factors. This paper has presented empirical evidence highlighting the need to move towards more dynamic interpretations of the complexities of what it is to 'be' a terrorist. The evidence from this paper indicates that in certain cases, individual and group resilience may be a protective factor when an individual faces negative experiences. It has also highlighted the similarities in protective factors between individuals who report psychological distress and those who do not, suggesting that the presence of protective factors is not be sufficient to explain why groupactor terrorists present with a lower than expected prevalence of mental disorder.

\section{Acknowledgements}


Funding: This research was, in part, supported by the Office of University Programs Science and Technology Directorate of the U.S. Department of Homeland Security through the Center for the Study of Terrorism and Behavior (CSTAB - Center Lead) Grant made to the START Consortium (Grant \# 2012-ST-61-CS0001). The views and conclusions contained in this document are those of the authors and should not be interpreted as necessarily representing the official policies, either expressed or implied, of the U.S. Department of Homeland Security, or START. 


\section{Bibliography}

Agnew, R. (2010). A general strain theory of terrorism. Theoretical Criminology, 14(2), 131153.

Aldwin, C. M., Levenson, M. R., \& Spiro, A. (1994). Vulnerability and resilience to combat exposure: Can stress have lifelong effects? Psychology and Aging, 9(1), 34-44.

Altier, M. B., Horgan, J., \& Thoroughgood, C. 2012. In their own words? Methodological considerations in the analysis of terrorist autobiographies. Journal of Strategic Security, 5(4), 85-98.

Altier, M. B., Leonard, E., Shortland, N., \& Horgan, J. (2017). Why they leave: An analysis of terrorist disengagement events from eighty-seven autobiographical accounts. Security Studies, 26(2), 305-332.

Başoğlu, M., Paker, M., Paker, Ö., Özmen, E., Marks, I., Incesu, C., .. \& \& Sarimurat, N. (1994). Psychological effects of torture: A comparison of tortured with nontortured political activists in Turkey. American Journal of Psychiatry, 151(1), 76-81.

Baumeister, R. F., Bratslavsky, E., Finkenauer, C., \& Vohs, K. D. (2001). Bad is stronger than good. Review of General Psychiatry, 5(4), 323-370.

Berney, L. R., \& Blane, D. B. (1997). Collecting retrospective data: Accuracy of recall after 50 years judged against historical records. Social Science and Medicine, 45(10), 1519-1525.

Beune, K., Giebels, E., \& Taylor, P. J. (2010). Patterns of interaction in police interviews: The role of cultural dependency. Criminal Justice and Behavior, 37(8), 904-925. 
Bonanno, G. A. (2004). Loss, trauma, and human resilience: Have we underestimated the human capacity to thrive after extremely aversive events? American Psychologist, 59(1), 2028.

Born, M., Chevalier, V., \& Humblet. I. (1997). Resilience, desistance and delinquent career of adolescent offenders. Journal of Adolescence, 20(6), 679-694.

Bubolz, B. F., \& Simi, P. (2019). The problem of overgeneralization: The case of mental health problems and U.S. violent white supremacists. American Behavioral Scientist, 1-17.

Burton, D., Foy, D., Bwanausi, C., Johnson, J., \& Moore, L. (1994). The relationship between traumatic exposure, family dysfunction, and post-traumatic stress symptoms in male juvenile offenders. Journal of Traumatic Stress, 7(1), 83-93.

Cauffman, E., Feldman, S., Waterman, J., \& Steiner, H. (1998). Posttraumatic Stress Disorder among female juvenile offenders. Journal of American Academy of Child and Adolescent Psychiatry, 37(11), 1209-1217.

Clarke, D. D., Forsyth, R., \& Wright, R. (1999). Junction road accidents during cross-flow turns: A sequence analysis of police case files. Accident Analysis \& Prevention, 31(1-2), 3143.

Cohen, S., \& Wills, T. A. (1985). Stress, social support, and the buffering hypothesis. Psychological Bulletin, 98(2), 310-357. 
Conway, M. A., \& Pleydell-Pearce, C. W. (2000). The construction of autobiographical memories in the self-memory system. Psychological Review, 107(2), 261-288.

Cordes, B. (1987). When terrorists do the talking: Reflections on terrorist literature. Journal of Strategic Studies, 10(4), 150-171.

Corner, E., \& Gill, P. (2015). A false dichotomy? Mental illness and lone-actor terrorism. Law and Human Behavior, 39(1), 23-34.

Corner, E., Gill, P., \& Mason, O. (2016). Mental health disorders and the terrorist: A research note probing selection effects and disorder prevalence. Studies in Conflict \& Terrorism, 6, 560568.

Corner, E., Bouhana, N., \& Gill, P. (2019). The Multifinality of vulnerability indicators in loneactor terrorism. Psychology, Crime \& Law, 25(2), 111-132.

Daumantas, J. (1975). Fighters for freedom: Lithuanian partisans versus the U.S.S.R. 19441947. New York, NY: Maryland Books.

Derogatis, L. R., \& Fitzpatrick, M. (2004). The SCL-90-R, the Brief Symptom Inventory (BSI), and the BSI-18. In M. E. Maruish (Ed.), The use of psychological testing for treatment planning and outcomes assessment: Instruments for adults (pp. 1-41). Mahwah, NJ, US: Lawrence Erlbaum Associates Publishers.

Dohrenwend, B. S., \& Dohrewend, B. P. (1981). Socioenvironmental factors, stress, and psychopathology. American Journal of Community Psychology, 9(2), 128-164. 
Drury, J., Cocking, C., \& Reicher, S. (2009). The nature of collective resilience: Survivor reactions to the 2005 London bombings. International Journal of Mass Emergencies and Disasters, 27(1), 66-95.

Dumont, M., \& Provost, M. A. (1999). Resilience in adolescents: Protective role of social support, coping strategies, self-esteem, and social activities on experience of stress and depression. Journal of Youth and Adolescence, 28(3), 343-363.

DuPaul, G. J., Schaughency, E. A., Weyandt, L. L., Tripp, G., Kiesner, J., Ota, K., \& Stanish, H. (2001). Self-report of ADHD symptoms in university students: Cross-gender and crossnational prevalence. Journal of Learning Disabilities, 34(4), 370-379.

Fletcher, D., \& Sakar, M. (2013). Psychological resilience: A review and critique of definitions, concepts, and theory. European Psychologist, 18(1), 12-23.

Fossi, J. J., Clarke, D. D., \& Lawrence, C. (2005). Bedroom rape: Sequences of sexual behavior in stranger assaults. Journal of Interpersonal Violence, 20(11), 1444-1466.

Franke, G. H., Jaeger, S., Glaesmer, H., Barkmann, C., Petrowski, K., \& Braehler, E. (2017). Psychometric analysis of the brief symptom inventory 18 (BSI-18) in a representative German sample. BMC Medical Research Methodology, 17(14), 1-7.

Garmezy, N. (1983). Stressors of Childhood. In G. Norman, \& M. Rutter (Eds.), Stress, Coping, and Development in Children (pp. 43-84). Blatimore, MD: Johns Hopkins University Press.

Giebels, E., \& Taylor, P., J.. (2009). Interaction patterns in crisis negotiations: Persuasive arguments and cultural differences. Journal of Applied Psychology, 94(1), 5-19. 
Gill, P., \& Corner, E. (2017). There and back again: The study of mental disorder and terrorist involvement. American Psychologist, 72(3), 231-241.

Gill, P., Horgan, J., \& Deckert, P. (2014). Bombing alone: Tracing the motivations and antecedent behaviors of lone-actor terrorists. Journal of Forensic Sciences, 59(2), 425-435.

Gooding, P. A., Hurst, A., Johnson, J., \& Tarrier, N. (2012). Psychological resilience in young and older adults. International Journal of Geriatric Psychiatry, 27(3), 262-270.

Gottman, J., Markman, H., \& Notarius, C. (1977). The topography of marital conflict: A sequential analysis of verbal and nonverbal behavior. Journal of Marriage and Family, 39(3), 461-477.

Hansen, A. (2002). Direct action: Memoirs of an urban guerilla. Toronto, Ontario: Between the Lines.

Hasselbach, I., Reiss, T. (1996). Führer-Ex: Memoirs of a former neo-nazi. New York, NY: Random House.

Hecker, T., Hermenau, K., Maedl, A., Hinkel, H., Schauer, M., \& Elbert, T. (2013). Does perpetrating violence damage mental health? Differences between forcibly recruited and voluntary combatants in DR Congo. Journal of Traumatic Stress, 26(1), 142-148.

Herman-Stahl, M., \& Anne C. Petersen, A. C. (1996). The protective role of coping and social resources for depressive symptoms among young adolescents. Journal of Youth and Adolescence, 25(6), 733-753. 
Hobfoll, S. E., Canetti-Nisim, D., \& Johnson, R. J. (2006). Exposure to terrorism, stress-related mental health symptoms, and defensive coping among Jews and Arabs in Israel. Journal of Consulting and Clinical Psychology, 74(2), 207-218.

Hoge, C. W., Castro, C. A., Messer, S. C., McGurk, D., Cotting, D. I., \& Koffman, R. L. (2004). Combat duty in Iraq and Afghanistan, mental health problems, and barriers to care. New England Journal of Medicine, 351(1), 13-22.

Horgan, J. (2003). The Search for the Terrorist Personality. In A. Silke (Ed.), Terrorists, victims and society: Psychological perspectives on terrorism and its consequences (pp. 3-27). Chichester, England: Wiley.

Horgan, J., Altier, M. B., Shortland, N., \& Taylor, M. (2017). Walking away: The disengagement and deradicalization of a violent right-wing extremist. Behavioral Sciences of Terrorism and Political Aggression, 9(2), 63-77.

Hugenberg, K., \& Bodenhausen, G. V. (2004). Category membership moderates the inhibition of social identities. Journal of Experimental Social Psychology, 40(2), 233-238.

Jacques, K. (2010). An exploration of female mobilisation into terrorism. (Unpublished Doctoral Thesis, University of Lancaster, UK).

Jacques, K., \& Taylor, P. J. (2007, September). Pathways to suicide terrorism: Do women follow in men's footsteps? Poster presented at the BPS Division of Social Psychology conference, Kent. 
Kaniasty, K., \& Norris, F. H. (2008). Longitudinal linkages between perceived social support and posttraumatic stress symptoms: Sequential roles of social causation and social selection. Journal of Trauma and Stress, 21(3), 274-281.

Kessler, R. C., \& Üstün, T. B. (2008). The WHO world mental health surveys: Global perspectives on the epidemiology of mental disorders. Cambridge, England: Cambridge University Press.

Kim, H. S., Sherman, D. K., \& Taylor, S. E. (2008). Culture and social support. American Psychologist, 63(6), 518-526.

Krippendorff, K. (2004). Reliability in content analysis: Some common misconceptions and recommendations. Human Communication Research, 30(3), 411-433.

Lakey, B., Tardiff, T. A., \& Drew, J. B. (1994). Negative social interactions: Assessment and relations to social support, cognition, and psychological distress. Journal of Social and Clinical Psychology, 13(1), 42-62.

Li, X., Stanton, B., Pack, R., Harris, C., Cottrell, L., \& Burns, J. (2002). Risk and protective factors associated with gang involvement among urban African American adolescents. Youth \& Society, 34(2), 172-194.

Mackie, D. M., Silver, L. A., \& Smith, E. R. (2004). Intergroup emotions: Emotion as an intergroup phenomenon. In L. Z. Tiedens \& C. W. Leach (Eds.), The social life of emotions (pp. 227-245). Cambridge, England: Cambridge University Press. 
McCauley, C. (2004). Psychological issues in understanding terrorism and the response to terrorism. In C. E. Stout (Ed.), Psychology of terrorism: Coping with the continuing threat, (pp. 33-65). Westport, CT: Praeger Publishers.

Milliken, C. S., Auchterlonie, J. L., \& Hoge, C. W. (2007). Longitudinal assessment of mental health problems among active and reserve component soldiers returning from the Iraq war." JAMA, 298(18), 2141-2148.

Monahan, J. (2015). The individual risk assessment of terrorism: Recent developments. Virginia Public Law and Legal Theory Research Paper No.57.

Neo, L. S., Dillon, L., \& Khader, M. (2017). Identifying individuals at risk of being radicalised via the internet. Security Journal, 30(4), 1112-1133.

Ong, A. D., Bergeman, C. S., Bisconti, T. L., \& Wallace, K. A. (2006). Psychological resilience, positive emotions, and successful adaptation to stress in later life. Journal of Personality and Social Psychology, 91(4), 730-749.

Papanastassiou, M., Waldron, G., Boyle, J., Chesterman, L. P. (2004). Post-Traumatic Stress Disorder in mentally ill perpetrators of homicide. The Journal of Forensic Psychiatry \& Psychology, 15(1), 66-75.

Paton, D., Violanti, J. M., Johnston, P., Burke, K. J., Clarke, J., \& Keenan, D. (2008). Stressshield: A model of police resiliency. International Journal of Emergency Mental Health, 10, 95-107. 
Pillemer, D. B., Goldsmith, L. R., Panter, A. T., \& White, S. H. (1988). Very long-term memories of the first year in college. Journal of Experimental Psychology: Learning, Memory, and Cognition, 14(4), 709-715.

Post, J. M., Sprinzak, E., \& Denny, L. (2003). The terrorists in their own words: Interviews with 35 incarcerated middle eastern terrorists. Terrorism and Political Violence, 15(1), 171184.

Pressman, D. E., Duits, N., Rinne, T., \& Flockton, J. S. (2018). VERA - 2R Violent Extremism Risk Assessment - Version 2 Revised: A structured professional judgement approach. Utrecht, Netherlands: Netherlands Institute of Psychiatry and Psychology.

Pressman, D. E., \& Flockton, J. (2012). Calibrating risk for violent political extremists and terrorists: The VERA 2 structured assessment. The British Journal of Forensic Practice, 14(4), 237-251.

Ross, J. I. (2004). Taking stock of research methods and analysis on oppositional political terrorism. The American Sociologist, 35(2), 26-37.

Rotella, S. (2004). Social bonds pull Muslim youth to jihad, Expert Says. Los Angeles Times. Retrieved from http://articles.latimes.com

Rubin, D. C., Rahhal, T. A., Poon, L. W. (1998). Things learned in early adulthood are remembered best. Memory and Cognition, 26(1), 3-19.

Rubin, T. A., Wetzler, S. E., \& Nebes, R. D. (1986). Autobiographical memory across the lifespan. In D. C. Rubin (Ed.), Autobiographical Memory, (pp. 202-224). Cambridge, England: Cambridge University Press. 
Shapiro, J. (2013). The terrorist's dilemma: Managing violent covert organisations. Princeton, NJ: Princeton University Press.

Sprinzak, E. (1990). The psychopolitical formation of extreme left terrorism in a democracy: The case of the weathermen. In W. Reich (Ed.), Origins of terrorism: Psychologies, ideologies, theologies and states of mind (pp. 65-85). Washington DC: Cambridge University Press.

Stern, S. (1975). With the Weathermen: The personal journey of a revolutionary woman. Garden City, NJ: Doubleday \& Company.

Swann, W. B., Jetten, J., Gomez, A., Whitehouse, H., \& Bastian, B. (2012). When group membership gets personal: A theory of identity fusion. Psychological Review, 119(3), 441456.

Taylor, O., D. A. Keatley., and D. D. Clarke. (2017). A behavior sequence analysis of perceptions of alcohol-related violence surrounding drinking establishments. Journal of Interpersonal Violence, 1-16.

Taylor, P. J. (2006). Proximity coefficients as a measure of interrelationships in sequences of behavior. Behavior Research Methods, 38(1), 32-50.

Taylor, P. J., \& Donald, I. (2007). Testing the relationship between local cue-response patterns and the global structure of communication behaviour. British Journal of Social Psychology, 46(2), 273-298.

Taylor, P. J., Jacques, K., Giebels, E., Levine, M., Best, R., Winter, J., \& Rossi, G. (2008). Analysing forensic processes: Taking time into account. Issues in Forensic Psychology, 8, 4557. 
Turner, J. C., Oakes, P. J., Haslam, S. A., \& McGarty, C. (1994). Self and collective: Cognition and social context. Personality and Social Psychology, 20(5), 454-463.

Ucros, C. G. (1989). Mood state-dependent memory: A meta-analysis. Cognition and Emotion, 3(2), 139-167.

Ungar, M. (2013). Resilience, trauma, context, and culture. Trauma, Violence, \& Abuse, 14(3), 255-266.

Walker, R. W., Vogl, R. J., \& Thompson, C. P. (1997). Autobiographical memory: Unpleasantness fades faster than pleasantness over time. Applied Cognitive Psychology, 11(5), 399-413.

Waugh, C. E., Fredrickson, B. L., \& Taylor, S. F. (2008). Adapting to life's slings and arrows: Individual differences in resilience when recovering from an anticipated threat. Journal of Research in Personality, 42(4), 1031-1046.

Weatherston, D., \& Moran, J. (2003). Terrorism and mental illness: Is there a relationship? International Journal of Offender Therapy and Comparative Criminology, 47(6), 698-713.

Wheaton, B. (1985). Models for the stress-buffering functions of coping resources. Journal of Health and Social Behavior, 26(4), 352-364.

White, M. D., Mulvey, P., Fox, A. M., \& Choate, D. (2012). A hero's welcome? Exploring the prevalence and problems of military veterans in the arrestee population. Justice Quarterly, 29(2), 258-286. 
Wilson, A. E., \& Ross, M. (2001). From chump to champ: People's appraisals of their earlier and present selves. Journal of Personality and Social Psychology, 80(4), 572-584.

Wilson, A. E., \& Ross, M. (2003). The identity function of autobiographical memory: Time is on our side. Memory, 11(2), 137-149.

World Health Organisation. (2010). ICD-10: International statistical classification of diseases and health problems $\left(10^{\text {th }}\right.$ rev $)$ Retrieved from http://www.who.int/classifications/icd/en/

Zebel, S., Doosje, B., \& Spears, R. (2009). How Perspective-taking helps and hinders groupbased guilt as a function of group identification." Group Processes \& Intergroup Relations, 12(1), 61-78. 


\section{Biographical Notes}

Emily Corner, BSc, MSc, $\mathrm{PhD}$, is a Senior Lecturer of criminology in the Centre for Social Research and Methods at the Australian National University. She has worked on research projects funded by Defence Science and Technology Laboratory, the European Union, the National Institute of Justice, the Department of Defence, and the Department of Home Affairs. She has extensive experience in undertaking systematic quantitative and qualitative research relating to lone and group-based terrorism, radicalisation, mass murderers, grievance-fuelled violence, and fixated individuals. Dr Corner's doctoral research focused on examining mental disorders and terrorist behaviour, and won the Terrorism Research Initiative's Thesis award in 2016. Her published works focus on decision making and mental health in lone and groupbased terrorism, radicalisation, mass murderers, and fixated individuals. [Email: emily.corner@anu.edu.au]

Paul Gill is Professor of Security and Crime Science at University College London. He has conducted research funded by the Office for Naval Research, the Department of Homeland Security, DSTL, the European Union, the National Institute of Justice, CREST, Public Safety Canada and MINERVA. He currently manages European Research Council Starter Grant project entitled GRIEVANCE. These projects focus upon various aspects of terrorist behaviour, including IED development, creativity, terrorist network structures, risk assessment and management, and lone-actor terrorism. His doctoral research focused on the underlying individual and organizational motivations behind suicide bombing. He has published in leading psychology, criminology and political science journals. 
Table 1. Behavioural Sequence and Resulting Proximity Coefficient Matrix

\begin{tabular}{lcccccc}
\hline & & \multicolumn{5}{c}{ Behavior-Type } \\
\cline { 2 - 7 } Behavioral Sequence & Behaviour-Type & A & B & C & D & E \\
\hline & A & 0.250 & 0.750 & 1 & 0.750 & 0.875 \\
A C E D D B E A B E & B & 0.875 & 0.750 & -- & -- & 1 \\
& C & 0.375 & 0.625 & -- & 0.875 & 1 \\
& D & 0.688 & 0.938 & -- & 1 & 0.812 \\
& E & 0.750 & 0.812 & -- & 1 & 0.688 \\
\hline
\end{tabular}


Table 2. Significant associations between Early Life Experiences and Psychological Distress

\begin{tabular}{lcccc}
\hline Experience & \multicolumn{2}{c}{ Psychological Distress } & \multicolumn{2}{c}{ No Psychological Distress } \\
& $\%$ & $\mathrm{n}$ & $\%$ & $\mathrm{n}$ \\
\hline Caretaker Physically Abusive & $61.9^{* * *}$ & 13 & 21.4 & 15 \\
Caretaker Verbally Abusive & $23.8^{*}$ & 5 & 5.7 & 4 \\
Familial History of Mental & $33.3^{* * *}$ & 7 & 7.1 & 5 \\
Disorder & & & & 3 \\
Good Relationships with & 23.8 & 5 & $44.3^{*}$ & \\
Family & & 0 & $21.4^{*}$ & 15 \\
Children & 0.0 & 13 & 35.7 & 25 \\
Involved in Criminal & $61.9^{*}$ & & & 2 \\
Behaviour & & 12 & 2.9 & 7 \\
Loner & $57.1^{* * *}$ & 11 & 10.0 & 7 \\
Alcohol Abuse & $38.1^{* *}$ & $52.4^{* * *}$ & 10.0 & \\
Drug Abuse & & & &
\end{tabular}

NB: $* p<.05, * * p<.01, * * * p<.005$ 
Table 3. Coefficient Matrix for Experiences of Individuals with No Recorded Psychological Distress

\begin{tabular}{|c|c|c|c|c|c|c|c|c|c|}
\hline & $\begin{array}{c}\text { Caretaker } \\
\text { Physically } \\
\text { Abusive }\end{array}$ & $\begin{array}{l}\text { Caretaker } \\
\text { Verbally } \\
\text { Abusive }\end{array}$ & $\begin{array}{c}\text { Familial } \\
\text { History of } \\
\text { Mental } \\
\text { Disorder }\end{array}$ & $\begin{array}{c}\text { Good } \\
\text { Relationship } \\
\text { with Family }\end{array}$ & Children & $\begin{array}{c}\text { Involved in } \\
\text { Criminal } \\
\text { Behaviour }\end{array}$ & Loner & $\begin{array}{l}\text { Alcohol } \\
\text { Abuse }\end{array}$ & $\begin{array}{l}\text { Drug } \\
\text { Abuse }\end{array}$ \\
\hline Caretaker Physically Abusive & ---- & 1 & ---- & 0.685 & 0.487 & 0.614 & 0.774 & 0.800 & 0.740 \\
\hline Caretaker Verbally Abusive & ---- & ---- & 1 & 1 & 0.800 & 0.681 & ---- & ---- & ---- \\
\hline $\begin{array}{l}\text { Familial History of Mental } \\
\text { Disorder }\end{array}$ & ---- & --- & 0.163 & 0.400 & ---- & 0.625 & --- & 0.750 & 0.625 \\
\hline Good Relationship with Family & 0.109 & ---- & 0.500 & 0.003 & 0.393 & 0.567 & 0.875 & 0.812 & 0.774 \\
\hline Children & ---- & ---- & ---- & ---- & 0.226 & ---- & ---- & ---- & ---- \\
\hline Involved in Criminal Behaviour & ---- & --- & ---- & --- & 0.785 & 0.065 & ---- & 0.188 & 0.373 \\
\hline Loner & ---- & ---- & ---- & ---- & ---- & 0.538 & ---- & ---- & 0.778 \\
\hline Alcohol Abuse & ---- & ---- & ---- & ---- & ---- & 0.834 & ---- & 0.138 & 0.844 \\
\hline Drug Abuse & ---- & ---- & ---- & 0.636 & 0.766 & 0.766 & ---- & 0.333 & 0.058 \\
\hline
\end{tabular}

NB ---- = No coefficient generated as behaviour never occurred prior 
Table 4. Coefficient Matrix for Experiences of Individuals with Recorded Psychological Distress

\begin{tabular}{|c|c|c|c|c|c|c|c|c|c|}
\hline & $\begin{array}{c}\text { Caretaker } \\
\text { Physically } \\
\text { Abusive }\end{array}$ & $\begin{array}{c}\text { Caretaker } \\
\text { Verbally } \\
\text { Abusive }\end{array}$ & $\begin{array}{c}\text { Familial } \\
\text { History of } \\
\text { Mental } \\
\text { Disorder }\end{array}$ & $\begin{array}{c}\text { Good } \\
\text { Relationship } \\
\text { with Family }\end{array}$ & $\begin{array}{c}\text { Psychological } \\
\text { Distress }\end{array}$ & $\begin{array}{c}\text { Involved } \\
\text { in } \\
\text { Criminal } \\
\text { Behaviour }\end{array}$ & Loner & $\begin{array}{l}\text { Alcohol } \\
\text { Abuse }\end{array}$ & $\begin{array}{l}\text { Drug } \\
\text { Abuse }\end{array}$ \\
\hline $\begin{array}{l}\text { Caretaker Physically } \\
\text { Abusive }\end{array}$ & $\begin{array}{c}--- \\
-1\end{array}$ & 0.750 & 0.959 & 1 & 0.550 & 0.627 & 0.744 & 0.569 & 0.443 \\
\hline Caretaker Verbally Abusive & 0.250 & ---- & 0.988 & ---- & 0.715 & 0.626 & 0.463 & 0.335 & 0.378 \\
\hline $\begin{array}{l}\text { Familial History of Mental } \\
\text { Disorder }\end{array}$ & ---- & ---- & ---- & ---- & 0.773 & 0.741 & 0.606 & 0.428 & 0.453 \\
\hline $\begin{array}{l}\text { Good Relationship with } \\
\text { Family }\end{array}$ & ---- & ---- & ---- & ---- & 0.506 & 0.596 & 1 & 0.641 & 0.833 \\
\hline Psychological Distress & ---- & ---- & ---- & ---- & 0.078 & 0.505 & 0.182 & 0.577 & 0.626 \\
\hline $\begin{array}{l}\text { Involved in Criminal } \\
\text { Behaviour }\end{array}$ & ---- & ---- & ---- & --- & 0.372 & 0.058 & 0.321 & 0.903 & 0.541 \\
\hline Loner & ---- & 0.292 & 0.167 & ---- & 0.720 & 0.458 & ---- & 0.753 & 0.688 \\
\hline Alcohol Abuse & ---- & ---- & ---- & ---- & 0.330 & 0.304 & ---- & ---- & 1 \\
\hline Drug Abuse & ---- & ---- & ---- & ---- & 0.282 & 0.370 & ---- & ---- & ---- \\
\hline
\end{tabular}

NB ---- = No coefficient generated as behaviour never occurred prior 
Table 5. Significant Associations between Group Relationship Experiences and Psychological Distress

\begin{tabular}{|c|c|c|c|c|}
\hline \multirow[t]{2}{*}{ Experience $^{12}$} & \multicolumn{2}{|c|}{ Psychological Distress } & \multicolumn{2}{|c|}{ No Psychological Distress } \\
\hline & $\%$ & $\mathbf{n}$ & $\%$ & n \\
\hline Individual was a $\mathrm{Spy}^{13}$ & $19.6^{* *}$ & 10 & 3.4 & 2 \\
\hline Poor Relationship with & $17.6^{* *}$ & 9 & 1.7 & 10 \\
\hline Leaders & & & & \\
\hline Retain ties with Family \& & $72.5^{* *}$ & 37 & 44.8 & 26 \\
\hline Friends not in group & & & & \\
\hline $\begin{array}{l}\text { Trouble Balancing Marriage } \\
\text { with Activities }\end{array}$ & $89.7 *$ & 26 & 66.7 & 26 \\
\hline $\begin{array}{l}\text { Trouble Balancing Children } \\
\text { with Activities }\end{array}$ & $84.6^{*}$ & 22 & 57.1 & 16 \\
\hline
\end{tabular}

NB: $* p<.05, * * p<.01, * * * p<.005$

Note that with Bonferroni correction, the adjusted $p$-value for significance is .003

\footnotetext{
${ }^{12}$ Some actors experienced multiple engagements, and each period of engagement was subject to examination. This resulted in 109 observations for engagement periods.

${ }^{13}$ It is expected that individuals who acted as spies for government entities during their engagement would not undergo identity fusion to the extent that other actors would.
} 
Appendix 1

Groups within Autobiographies 
African National Congress

African Resistance Movement

American Firm

Arab Nationalist Movement

Chicago Area Skinheads

Confederación Nacional del Trabajo

Communist Party of Germany

Communist Party of the Philippines

Cumann na mBan

Direct Action

Ethniki Organosis Kyprion Agoniston

Fatah

Front de libération du Québec

Frente Sandinista Liberacion Nacional

Glasgow Anarchist Group

Groupe Islamique Arme

Hamas

Hammerskins

Harakat-ul Jihad

Hizb ut-Tahrir

Iberian Federation of Libertarian Youth

Irgun Zvai Leumi

Irish National Liberation Army

Irish Republican Army

Irish Republican Brotherhood

Irish Volunteers

Jama-e-Islami

June 2nd Movement

Kenya African Union

Ku Klux Klan

Lehi

Lithuanian Freedom Council
Lord's Resistance Army

Mau Mau

Minutemen

Moveimiento 19 de Abril

Movement of the 30th of January

MPLA

Muslim Brotherhood

Northern Hammer Skinheads

Na Fianna

National Socialist German Workers Party

Northern Hammer Skinheads

Palestine Liberation Organisation

Polish Underground

Popular Front for the Liberation of Palestine

Provisional Irish Republican Army

Red Army Faction

Red Hand Commando

Romantic Violence

Seattle Liberation Front

Skinhead Army of Milwaukee

South African Communist Party

South African Indian Congress

South West African People's Organisation

Spartacus League

The Covenant Sword and Arm of the Lord

The National Alternative

The Weathermen

Ulster Defence Association

Ulster Volunteer Force

Umkhonto we Sizwe

Xhi

Zimbabwe African People's Union 